\title{
Mating success of male hermit crabs in shell generalist and shell specialist species
}

\author{
Brian A. Hazlett \\ Department of Biology, University of Michigan, Ann Arbor, MI 48109, USA
}

Received January 9, 1989 / Accepted May 7, 1989

Summary. The reproductive behavior of two species of diogenid hermit crabs was studied in Hawaii. In the shell generalist, Clibanarius zebra, male reproductive success varied little with size, although the largest males were less successful in obtaining copulations than were medium-large males. Male and female size were positively correlated, in successful pairs, thus larger males had the potential to fertilize more eggs when they were successful in obtaining a copulation. Female fecundity in $C$. zebra was not affected by species of gastropod shell inhabited once female size was taken into account. Male copulatory success was very strongly influenced by the species of gastropod shell inhabited. Males in Trochus or Nerita shells had greatly reduced reproductive success compared to males in Turbo or Nassarius shells. This result was due both to (1) males in Trochus especially dropping and otherwise poorly handling females during precopulatory behavior and (2) females not responding to precopulatory behavior patterns executed by males in Trochus and Nerita. Transferring males from "good" to "bad" shapes of shells and vice versa showed that male success was a function of shell type inhabited and not some correlated feature of the crabs. In the shell specialist, Calcinus seurati, which is found primarily in Nerita shells as an adult, males in Nerita shells were quite successful in obtaining copulations.

\section{Introduction}

The reproductive success of males in a wide variety of species varies depending upon the resources held by those males. In many cases, this would appear to be a result of female choice among the males with different quantities or quality of resources. When the resources of the male contribute to fe- male and/or offspring survival, the basis of female choice seems clear. In cases where the male's resources do not appear to contribute to female or offspring survival or growth, the question of the ultimate bases of female choice is even more interesting (Borgia 1979). Observations on the intertidal hermit crab Calcinus tibicen in Jamaica indicated very dramatic differences in male reproductive success depending upon the species of gastropod shell occupied (Hazlett \& Baron, in press). In particular, the largest males in the population obtained very few matings apparently as a result of the kinds of shells available to crabs in that size range.

The current study was undertaken as a first step towards examining the generality of the pattern seen in C. tibicen. In particular, the reproductive behavior of a species which, like $C$. tibicen, occupies a wide variety of species of shells was examined as well as the behavior shown by individuals in a species which could be characterized as a shell specialist. The shell generalist studied was the intertidal diogenid Clibanarius zebra which is the most common species in the intertidal zone in many areas of the Indo-Pacific. It occupies a wide array of species of gastropod shells (Reese 1968, 1969). The shell specialist studied was Calcinus seurati which is found almost exclusively in $\mathrm{Ner}$ ita species shells, probably as a consequence of the crab's ecological limitation to tide pools which are not regularily flushed by sea water. This restricted supra-tidal distribution (Reese 1969; Wooster 1984) results in a very limited array of gastropod shells available to individuals of this species. Since Nerita shells were a type which appeared to influence male reproductive success in a negative way in the congeneric shell generalist Calcinus tibicen (Hazlett \& Baron, in press), it was of particular interest to observe the patterns shown by a species largely restricted to that type of shell. 
The effects of shell type occupied were studied for both male and female reproductive success.

\section{Materials and methods}

Observations and measurements were made between January and May of 1988 on Ohau, Hawaii. Laboratory work was done at the Hawaii Institute of Marine Biology, Coconut Island, Kaneohe Bay, Ohau. All the individuals of Clibanarius zebra utilized were collected along the shores of Coconut Island while the specimens of Calcinus seurati used were collected from several supra-tidal locations around Ohau: Kapapa Island, Sandy Beach, Makapuu Point, and Shark Cove adjacent to Pupukea Beach Park.

Initial observations of precopulatory behavior patterns and copulation were made in the field on pairs of Clibanarius zebra. All data for quantitative analyses were taken in the laboratory at HIMB. Collections of specimens from the field were placed in water tables for observation of social interactions, including reproductive behavior. Between 150 and 300 crabs were maintained at a time and the area of the water table adjusted to maintain densities at approximately field levels. The concrete water table presented (to the crabs) a substrate that was quite similar to the rocky coral rubble in which they are normally found. For Calcinus seurati the crabs were kept in a portion of the water table with just that species present. In the case of Clibanarius zebra, the hermit crab population was similar to that found in the field with some individuals of other species present: Calcinus laevimanus, Calcinus latens and a few Calcinus elegans. After individual crabs engaged in either shell exchange or reproductive behaviors they were removed from the water table for measurements. Periodically new collections were added to the population under observation.

Observations were done between 0900 and $1600 \mathrm{hrs}$, at least several days a week between January and May. Whenever a pair of animals were seen in the opposed position (Hazlett 1966) with their shell aperatures facing, the observer's attention was directed to that pair and notes on their behavior patterns taken. While one pair was under observation, the rest of the water table was scanned for additional interactions. When more than five interactions were occurring similtaneously scanning ceased in order to focus on the pairs under direct observation. Data on shell exchange interactions were gathered for another study. Reproductive interactions were recognized by the execution of rotations by one animal of the other. This pattern is executed only by males in a number of diogenid species (Hazlett $1966,1972)$ and appears to be a necessary precursor to copulation. The common sequences of patterns observed during a precopulatory interaction are described for each species of crab in the Results section. For each pair engaged in a reproductive interaction the following data were taken: time of initiation of the interaction, number of rotations, inverse raps, and palpations by the male, time of the end of the interaction, and how the interaction ended (successful copulation, interruption by another crab such that that male no longer held the female, the male dropped the female while executing precopulatory patterns and she walked away from the male, or the male stopped holding the female and he walked away after some bouts of precopulatory patterns). After the interaction had ended, the pair of crabs was removed from the water table and placed in containers for later measurements. The data recorded for each male and female were: cephalothorax length (cl), moult state of the female, species of shell occupied, weight of the shell after drying at $80^{\circ} \mathrm{C}$ for at least $24 \mathrm{~h}$, and weight of the shell after drying and addition of fine, dry sand of known specific density. The latter allowed calculation of the internal volume of the shell.
To obtain a measure of the degree of shell fit, particularly of males engaged in reproductive behavior, the relationship between crab size and desired shell volume was estimated for two commonly occupied species of gastropod shell (Trochus intexus and Turbo sandwichensis). This was done by allowing 60 crabs access to about 200 empty shells in the appropriate size range for $24-48 \mathrm{~h}$. After this period of "free choice", the crabs were removed and size parameters measured. From those data the regression line between crab size and desired shell volume could be calculated.

To estimate the relationship between female size, shell occupation, and fecundity the number of eggs on the pleopods of a sample of females were counted. Female and shell parameters were also recorded. The primary source of these data for Clibanarius zebra was a collection made along the north shore of Coconut Island on February 24. All of the individuals of C. zebra collected were removed from their shells, sexed, cephalothorax length measured, and number of eggs counted in the case of females. The eggs on a given female were categorized as to age, either young (without eyespots on the embryos) or older (with eyespots on the embryos).

Based upon observations of Calcinus tibicen in Jamaica and of Clibanarius zebra in Hawaii, it appeared that males in certain species of gastropod shells were more successful in obtaining copulations than others. This could be the result of two different mechanisms: either the differential in success is caused by the occupation of the "good" vs "bad" shells or shell species occupation is just correlated with other behavior patterns exhibited by crabs. Two methods were used to try to choose between these alternative explanations. Males that were observed to successfully copulate (while occupying one species of shell) were, after measurements were made, placed in a different kind of shell (individually marked) and put back with the population of crabs under observation. The second method involved taking a number of males directly from the field and changing the kind of shell they occupied. Males in Trochus shells were removed from their shells and given free access to a number of empty Turbo shells for one hour and males in Turbo or Nassarius papillosus shells were removed and given free access to empty Trochus shells. These males were then placed in the observation area and over the next three days the occurrence of reproductive interactions monitored. The transferred males were kept in individual containers when not under observation.

The results of observations on shell species effects on reproduction of males and female $C$. zebra suggested that individuals of the two sexes might differ in their motivation to occupy different species of shells. Based upon fecundity and copulation success effects of shell species occupied, I predicted that males would change out of Trochus shells more readily than females when given the opportunity. To test this, animals were collected in the field that occupied either Trochus or Nassarius shells and placed in monospecific groups of 12 with 20 empty Turbo shells in the appropriate size range. 24 hours later the crabs were removed from the shells occupied and the number of males and females that had changed shell species recorded. Six replicates for each species of field-occupied shell were run.

\section{Results}

The shell species occupied in the field by the two species of hermit crabs are shown in Table 1. The predominance of Nerita species occupied by individuals of Calcinus seurati is in contrast to the variety of and eveness of species occupation by individuals of Clibarnarius zebra. 
Table 1. Shell occupation parameters for Clibanarius zebra and Calcinus seurati. Percentage of total for each gastropod species for field surveys. For $C$. zebra the percentage occupation of shells by known males is shown (the average for the February 24 field count and the males which were non-initiators in shell exchanges) and the mean size ( $\mathrm{mm} \mathrm{cl}$ ) for males in the February 24 survey

\begin{tabular}{|c|c|c|c|c|}
\hline & \multicolumn{3}{|c|}{ Clibanarius zebra } & \multirow{2}{*}{$\begin{array}{l}\text { Calcinus } \\
\text { seurati } \\
\% \text { overall } \\
(n=129)\end{array}$} \\
\hline & $\begin{array}{l}\% \text { overall } \\
(n=318)\end{array}$ & $\begin{array}{l}\% \text { by males } \\
(n=111)\end{array}$ & $\begin{array}{l}\text { mm cl males } \\
(n=41)\end{array}$ & \\
\hline Trochus & 49.0 & 52.2 & $9.0 \pm 1.0$ & 0 \\
\hline Nerita & 9.4 & 14.1 & $7.8 \pm 0.7$ & 82.3 \\
\hline Nassarius & 10.4 & 8.1 & $7.5 \pm 0.7$ & 0 \\
\hline Turbo & 5.0 & 17.4 & $9.0 \pm 0.8$ & 1.5 \\
\hline Drupella & 17.6 & 2.0 & 6.3 & 0 \\
\hline Littorina & 0.3 & 0 & - & 9.3 \\
\hline Morulla ova & 2.8 & 0 & - & 4.6 \\
\hline Strombus & 0 & 0 & - & 2.3 \\
\hline Natica & 3.7 & 3.7 & $8.2 \pm 1.1$ & 0 \\
\hline Others & 1.2 & 3.1 & - & 0 \\
\hline
\end{tabular}

The precopulatory patterns of Clibanarius zebra have not been described previously. Reese (1968) gives data on the fecundity and periodicity of egg-bearing in C. zebra. The precopulatory patterns of C. zebra are similar to those of other diogenid crabs, especially other species of Clibanarius (Hazlett 1966). The following summary is based upon notes taken during observations in 1969 , as well as the currently reported set of observations.

Unlike some congeners, in no case, of either courtship that resulted in copulation or those that ended without copulation, was the female C. zebra very recently moulted. In about a third of the cases, females had new eggs on their pleopods within two days of courtship, but the time of egg deposition was unknown in the majority of cases. In contrast to Calcinus tibicen (Hazlett and Baron, in press), no instances of courtship of a female carrying eggs was observed.

Courtship began with the male grasping and holding the shell of the female with his ambulatory legs. The male normally held the shell in the opposed position (Hazlett 1966), with the shell apertures facing one another. In this position, with the female just visible in the aperture of her shell, the male executed one or more bouts of the following patterns. Rotation: in this pattern the female shell was rotated about an axis perpendicular to and through the plane of the female shell aperture. Movement was through an arc of about $45^{\circ}$ and consisted of either a series of rotations or, more commonly in this species, a single cycle of movement. Inverse raps: in this pattern the female shell was rapidly drawn towards the male by flexion of his ambulatory legs. This pattern resembles the rapping movements executed during shell exchanges (Hazlett 1972) except that the female shell was the shell moved (in shell exchanges, the shell of the initiating/active crab is moved). In a few cases where the female shell was markedly heavier than the male's, his shell moved when his legs were flexed, rather than the female's. Inverse raps occurred either singly or in short bouts of 2-3 movements. Cheliped palpations: these were small, rapid movements of the male chelipeds lightly touching the female chelipeds. For each interaction, a measure of male activity, move rate, was calculated as the sum of the bouts of rotations and inverse raps divided by the number of minutes for the interaction.

In courtships that resulted in copulation as well as courtships that did not, one or all three of these patterns of male behavior were observed. After a few to many minutes of courtship, the female crabs sometimes moved forward slightly in her shell aperture and palpated the male's chelipeds and mouth parts with her chelipeds. He then eased partially out of his shell, exposing most of his cephalothorax and copulation occurred. As copulation occurred, the male flexed the posterior portion of his cephalothorax ventrally toward the female and she eased slightly out of her shell, exposing the ventral part of her cephalothorax. Copulation lasted only $5-10 \mathrm{~s}$ and was followed by only a minute or so of post-copulatory guarding by the male.

The number of bouts of precopulatory patterns preceeding successful copulation averaged seven, but was a few as one or two inverse raps in several instances.

\section{Fecundity of Clibanarius zebra}

In the sample of 221 female C. zebra examined, the number of eggs on a female's pleopods ranged from zero $(n=109)$ to 712 . Among the berried females which ranged from 4.7 to $8.6 \mathrm{~mm} \mathrm{cl}$, the mean number of eggs was $302 \pm 160(n=72)$ for those with eggs without eyespots and $349 \pm 166$ $(n=37)$ for those carrying eggs with eyespots. There was no difference in the number of younger vs older eggs $(t=1.43, d f=107, P>0.10)$. There was no difference in female cephalothorax length between those with young eggs and those with older eggs (means $=6.64$ and $6.67 \mathrm{~mm}$ cl respectively, $t=0.10, P>0.10)$.

There was no difference among the shell species occupied by individuals of $C$. zebra in the proportion of females that were berried (chi-square $=1.75$, $d f=5, P>0.10)$. In every shell species, about half 
Table 2. Fecundity parameters for Clibanarius zebra arranged by shell species occupied. All values are either counts or means (S.D.)

\begin{tabular}{|c|c|c|c|c|c|c|}
\hline \multirow[t]{2}{*}{ Shell species occupied } & \multirow[t]{2}{*}{ Total } & \multirow{2}{*}{$\begin{array}{l}\text { Number } \\
\text { unberried }\end{array}$} & \multirow{2}{*}{$\begin{array}{l}\text { Female } \\
\mathrm{cl} \mathrm{mm}\end{array}$} & \multicolumn{3}{|c|}{ Number of eggs } \\
\hline & & & & Overall & Young & Older \\
\hline Trochus & 74 & 38 & $7.1 \pm 0.6$ & 356 & $313 \pm 178$ & $467 \pm 225$ \\
\hline Nassarius & 42 & 23 & $6.5 \pm 0.3$ & 326 & $327 \pm 197$ & $325 \pm 97$ \\
\hline Nerita & 35 & 15 & $6.9 \pm 0.5$ & 328 & $300 \pm 109$ & $380 \pm 105$ \\
\hline Drupella & 54 & 25 & $6.1 \pm 0.5$ & 270 & $278 \pm 143$ & $259 \pm 118$ \\
\hline Morulla ova & 7 & 4 & & & & \\
\hline Other & 8 & 4 & & & & \\
\hline
\end{tabular}

of the females were carrying eggs. There was no difference among the shell species occupied in the proportion of berried females that were carrying young vs older embryos (chi-square $=3.19, d f=5$, $P>0.10$ ).

Across shell species occupied, the variation in number of eggs carried by berried females was very significantly reduced by consideration of female size (overall, number of eggs $=(114)(\mathrm{cl}$ in $\mathrm{mm}$ ) - 446, $r=0.529$, ANOVA F-ratio $=41.5, \quad P<$ 0.0001 ; number of young eggs $=(108)(\mathrm{cl} \mathrm{in} \mathrm{mm})$ $-420, r=0.51$, ANOVA $F$-ratio $=24.6, P<0.001$; number of older eggs $=(127)(\mathrm{cl}$ in $\mathrm{mm})-499, r=$ 0.58 , ANOVA $F$-ratio $=17.7, P<0.001$ ). In fact, female size was the only variable which explained variance in fecundity. Multiple regressions which encorporated other parameters (shell weight, shell species, volume of shell, or difference between currently occupied volume and desired volume for that species of shell) all failed to explain more variance than the single factor regression. In no case were additional parameters significant (all associated with $P>0.10$ ) once female size had been taken into account.

Thus even though females in Trochus shells appeared to carry more eggs on the average than females in Drupella elata shells (356 vs 270), this apparently was a result of Trochus shells being occupied by larger females on the average $(7.1 \mathrm{~mm}$ vs $6.1 \mathrm{~mm} \mathrm{cl}$ ). Using only the 104 cases from the four most commonly occupied shells (Fig. 1), there was no significant difference among shell species in the relationships between female size and number of eggs (analysis of covariance yielded a clearly insignificant interaction term for shell species and female size $(t=1.19, P=0.233)$.

In the case of females occupying Trochus shells, the number of eggs when the embryos had eyespots appeared higher than younger broods (467 vs 313 ), but this also appears to be a (chance) result of larger females ( 7.45 vs $7.01 \mathrm{~mm} \mathrm{cl}$ ) having more advanced young at the time of sampling. There

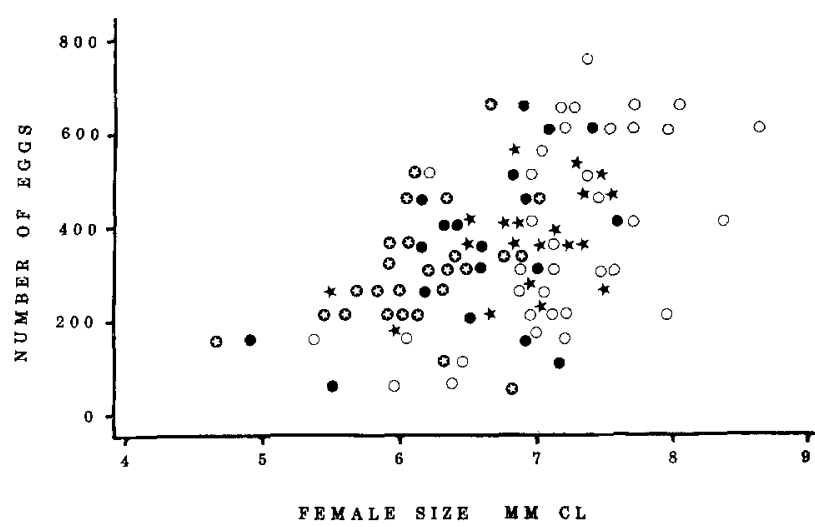

Fig. 1. Relationship between female cephalothorax length and number of eggs for Clibanarizs zebra. The different species of gastropod shells occupied by females were Trochus (0), Nassarius $(\bullet)$, Nerita $(\star)$, and Drupella $(\bullet)$

was no egg stage - female size interaction term in the analysis of covariance $(t=0.02, P=0.889)$.

While there was no shell species effect when all berried females were considered, it appeared as though an effect might be important in explaining the number of older embryos. Looking only at females carrying embryos with eyespots, there was a significant difference in the number of embryos among species (ANOVA $F=8.1, P=0.007$ ) but if female size is considered, no shell species effect is evident (multiple regression species $P=$ 0.785 , species-cl interaction $P=0.732$ ). That is, for any category of eggs analyzed, the number of eggs carried by a female is a function of size and not of shell species occupied.

\section{Reproductive interactions in Clibanarius zebra}

A total of 61 reproductive interactions were observed in $C$. zebra. These were recognized by the execution of at least one bout of either rotation or inverse raps, neither of which occur during other types of social interactions such as shell exchange 
Table 3. Male reproductive parameters for the 61 interactions involving Clibanarius zebra. Means and standard deviations for all features listed. Male volume deficit is in terms of $\mathrm{ml}$ of volume difference between volume of currently occupied shell and the desired volume for the species of shell. Move Rate is the sum of number of rotations plus number of inverse raps divided by the number of minutes

\begin{tabular}{llclc}
\hline Male away parameter & \multicolumn{2}{l}{ Interaction ended because } & & \\
\cline { 2 - 4 } & $\begin{array}{l}\text { Copulation } \\
(n=27)\end{array}$ & $\begin{array}{l}\text { Interruption } \\
(n=14)\end{array}$ & $\begin{array}{l}\text { Female dropped } \\
(n=16)\end{array}$ & $\begin{array}{l}\text { Male walk } \\
(n=4)\end{array}$ \\
\hline Male cl in mm & $8.4 \pm 1.3$ & $8.9 \pm 0.8$ & $9.0 \pm 1.1$ & $8.9 \pm 1.4$ \\
Vol Deficit & $0.4 \pm 0.5$ & $0.2 \pm 0.2$ & $0.3 \pm 0.2$ & $0.4 \pm 0.1$ \\
Rotations & $4.8 \pm 5.0$ & $5.8 \pm 6.0$ & $3.4 \pm 3.9$ & $8.2 \pm 9.1$ \\
Inverse Raps & $3.2 \pm 2.8$ & $1.1 \pm 1.4$ & $1.4 \pm 3.2$ & $1.5 \pm 2.3$ \\
Move Rate & $0.7 \pm 0.8$ & $1.0 \pm 1.3$ & $0.6 \pm 0.6$ & $0.7 \pm 0.9$ \\
Minutes & $25 \pm 28$ & $17 \pm 19$ & $20 \pm 33$ & $11 \pm 6$ \\
\hline
\end{tabular}

Table 4. Outcomes of reproductive interactions in Clibanarius zebra arranged by size of male ( $\mathrm{mm} \mathrm{cl)}$

\begin{tabular}{clllllr}
\hline Size in $\mathrm{mm}$ & $\begin{array}{l}\text { \% Success } \\
\text { in class }\end{array}$ & $\begin{array}{l}\text { Copulation } \\
\text { occurred }\end{array}$ & $\begin{array}{l}\text { Attempt } \\
\text { interrupted }\end{array}$ & $\begin{array}{l}\text { Dropped } \\
\text { female }\end{array}$ & $\begin{array}{l}\text { Walked } \\
\text { away }\end{array}$ & $\begin{array}{l}\text { Total } \\
\text { active }\end{array}$ \\
\hline $6.0-6.9$ & $75 \%$ & 3 & 0 & 1 & 0 & $4(6 \%)$ \\
$7.0-7.9$ & $64 \%$ & 7 & 2 & 1 & 1 & $11(18 \%)$ \\
$8.0-8.9$ & $44 \%$ & 8 & 5 & 4 & 1 & $18(29 \%)$ \\
$9.0-9.9$ & $13 \%$ & 2 & 5 & 3 & 1 & $15(25 \%)$ \\
$10.0+$ & $54 \%$ & 7 & 2 & 3 & $13 \%)$ \\
\hline
\end{tabular}

behavior. The number of minutes of interaction averaged 21.2. Of the 61 interactions, 27 resulted in copulation. Of the unsuccessful attempts, 14 ended due to interruption by another crab, 16 ended because the male dropped the female while attempting to execute precopulatory patterns, and in 4 cases the male smoothly released the female and he walked away (Table 3 ).

The size of the male (mean $=8.75 \mathrm{~mm}$ cl overall) did not appear to be important in determining reproductive success. That parameter alone did not significantly reduce the variance in the outcome of the interactions (ANOVA, $F=-3.62, P=$ 0.062 ) although the statistical value is close to the commonly accepted alpha level. As shown in Table 4 , the greatest number of copulations observed were obtained by males between 8.0 and $8.9 \mathrm{~mm}$ cl. However, this was the size class with the greatest representation in the reproductively active population and the proportion of active males obtaining copulations in that size class was rather low. There appears to be a decrease in the percentage success with size class from the $6 \mathrm{~mm}$ up to the $10 \mathrm{~mm}$ cl size classes $(75,64,44$, and $13 \%$ of the reproductively active males in each class obtaining copulations). It is only the relatively high success of males over $10.0(54 \%)$ which eleminates a significant negative relationship between size and reproductive success.

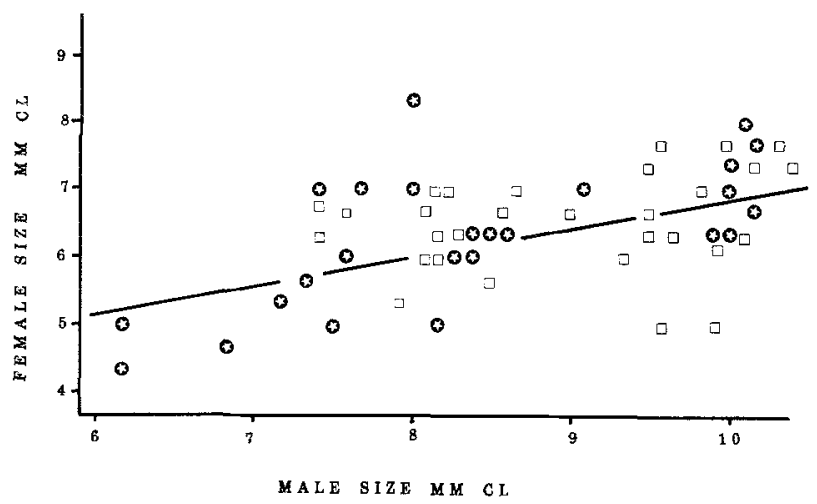

Fig. 2. Relationship between sizes of male and female Clibanarius zebra for pairs that did $(\$)$ or did not (a) copulate. The regression line (female $\mathrm{cl}=2.5+(0.43)$ (male cl)) is for copulating pairs only as there was no relationship for pairs that did not copulate

As shown in Fig. 2, there was a correlation between the sizes of crabs in pairs, but only for those courtships that resulted in copulation $(r=0.554$, $P<0.01)$. In the cases where copulation did not occur, there was no correlation between male and female cephalothorax length $(r=0.275, P>0.10)$.

The number of rotations executed by a male (mean $=4.8$ overall) did not vary between successful and unsuccessful interactions $(t=0.099, P=$ 0.921 ). However, the number of inverse raps were higher for interactions which resulted in copula- 
Table 5. Reproductive Interaction parameters categorized by shell species occupied by males. Outcome results are counts, for other parameters the mean values are given

\begin{tabular}{|c|c|c|c|c|c|c|c|c|}
\hline \multirow[t]{2}{*}{ Shell species } & \multirow{2}{*}{$\begin{array}{l}\text { Male cl } \\
\text { in } \mathrm{mm}\end{array}$} & \multirow{2}{*}{$\begin{array}{l}\text { Inverse } \\
\text { raps }\end{array}$} & \multirow{2}{*}{$\begin{array}{l}\text { Move } \\
\text { rate }\end{array}$} & \multirow[t]{2}{*}{ Minutes } & \multicolumn{4}{|c|}{ Outcome of interaction } \\
\hline & & & & & Copulation & Interrupted & Drop female & Walk away \\
\hline Trochus & 9.3 & 1.8 & 0.8 & 20 & 7 & 11 & 16 & 2 \\
\hline Nassarius & 7.3 & 2.0 & 0.4 & 24 & 6 & 0 & 0 & 0 \\
\hline Turbo & 10.1 & 2.7 & 0.4 & 16 & 3 & 0 & 0 & 0 \\
\hline Nerita & 7.6 & 2.3 & 0.8 & 22 & 3 & 3 & 0 & 2 \\
\hline Drupella & 7.4 & 0.6 & 0.2 & 24 & 3 & 0 & 0 & 0 \\
\hline Others & 7.4 & 6.0 & 1.7 & 24 & 5 & 0 & 0 & 0 \\
\hline Totals & & & & & 27 & 14 & 16 & 4 \\
\hline
\end{tabular}

tions $(t=2.7, P=0.009)$. The number of minutes of precopulatory behavior did not differ among the categories of outcome (ANOVA $F=1.00, P=$ $0.320)$ nor did it differ for the different species of shells occupied by males (ANOVA $F=0.16, P=$ 0.693 ).

The factor which reduced the variance in male reproductive success the most was shell species occupied. A regression using only shell species occupied by the male to explain variance in copulatory success was very significant (ANOVA $F=18.36$, $P<0.0001)$ and addition of other parameters to multiple regressions added little or nothing in terms of explaining additional variance. Male size $(t=0.269, P=0.789)$, move rate $(t=0.001, P=$ $0.999)$, male shell volume $(t=1.40, P=0.170)$, male shell weight $(t=0.479, P=0.635)$, male shell volume deficit $(t=0.009, P=0.998)$, or number of minutes in the interaction $(t=1.30, P=0.199)$ all explained no additional variance. Interaction terms between these parameters and shell species occupied were also all not significant in explaining additional variance. The number of inverse raps and the move rate of males in "other" shells species appears higher than that of males in Drupella, Turbo or Nassarius (Table 5) but the few cases observed $(n=5)$ were not sufficient to yield an effect on the overall ANOVA.

As shown in Table 5, the biggest factor in explaining the shell species occupied effect on male reproductive success is the behavior of crabs in Trochus shells compared to other species of shells. The category "dropped female" was filled completely by males in Trochus shells - all 16 cases were males in Trochus. In all these cases, the female crab quickly came to the aperture of her shell, got up, and walked away from the male or at least attempted to do so. Males in Nerita shells were also unsuccessful in a few cases while males in other genera of shells (Nassarius, Turbo, Drupella,
Natica, Strombus and Littorina) were uniformly successful in their courtship attempts.

If the proportions of shell species occupied by males in the population at large are used to calculate the number of males in different shell species which would be expected to engage in different categories of reproductive behavior two clear results are seen. The number of males in the various shell species that engage in reproductive activity (i.e. were observed as a member of a reproductive pair) is not different than that expected by chance given the pattern of shell occupation in the male population as a whole (chi-square $=7.2, d f=5, P>$ $0.10)$. However, the observed cases of copulation did differ very significantly from that which would be predicted on the frequencies of occupation in the general male population (chi-square $=15.99$, $d f=5, P<0.01$ ). In particular, males in Trochus shells obtained less copulations than expected while males in Nassarius, Drupella, and other less common species did better than expected. The gastropod shells occupied by males could be divided into two categories: "good" (Nassarius, Turbo, Drupella, and others) and "bad" (Trochus and Nerita).

\section{Putting males in different shells}

The first method used to test for direct effects of shell type of male success did not yield any clear results. None of the males (which were few in number at any point in time) engaged in further reproductive behavior, but rather they exchanged shells with other crabs. The experiment putting males into a different category of shells than they occupied in the field yielded quite clear results although the number of interactions observed was small. Of the males $(n=12)$ that were in Turbo and Nassarius shells and were forced to choose among empty Trochus shells, four males engaged 
in reproductive behavior. Of these four attempts, only one resulted in copulation. In two of the unsuccessful cases, the male dropped the female and she walked away. Of the males $(n=12)$ that were in Trochus shells and were placed in Turbo shells, three engaged in reproductive behavior. Of the three attempts, two resulted in copulation, while the third was interrupted by a male in a Nassarius shell. Thus it would appear that the patterns of success or failure to obtain copulations is a direct result of shell species occupied and not some correlated feature of the males who occupy particular shells.

\section{Shell changing tendency}

of male and female C. zebra

Among the six replicates testing the tendency of field collected animals to change from Trochus to Turbo and from Nassarius to Turbo, a total of 164 crabs was tested. Of these, 35 changed shell species $(21.3 \%)$ and the tendency was much higher for crabs of both sexes which occupied Trochus $(38.5 \%)$ compared to crabs in Nassarius shells $(3.7 \%)$ (Table 6).

Using the proportion of males changing overall (0.512) and females changing overall (0.107) and the numbers of each sex in each kind of shell, the expected number of crabs changing if there were no difference depending upon shell species occupied was calculated. The actual number changing was then compared and a chi-square value calculated. This value was 3.86 for males and 12.96 for females suggesting that females differentiated between the two species of shells (Trochus vs Nassarius) relatively more strongly than males. Certainly the hypothesis that males would change out of Trochus relatively more often than females was not supported by the data.

\section{Reproductive patterns of Calcinus seurati}

The precopulatory patterns of Calcinus seurati were described earlier (Hazlett 1972), based upon just one complete sequence of copulatory behavior. As in other Calcinus species, the primary patterns

Table 6. Number of Clibanarius zebra changing into Turbo shells from Trochus or Nassarius shells categorized by sex of crabs. Counts summed from six replicates

\begin{tabular}{|c|c|c|c|c|c|}
\hline & Trochus & to & Turbo & Nassarius to & Turbo \\
\hline Males & 31 & & 20 & 12 & 2 \\
\hline Females & 52 & & 12 & 69 & 1 \\
\hline
\end{tabular}

executed by males were rotations and cheliped palpations, with the latter being more common. In addition, in some cases the male rubbed his first right ambulatory leg along the edge of the shell aperture of the female. The first reproductive behaviors were seen on April 12 even though this species had been under close observation (and many other social interactions observed) since March 2. Males were between 36 and 109\% larger in $\mathrm{cl}$ than the females they were interacting with, average of $64 \%$ larger.

In the interactions observed in 1988, the amount of precopulatory behavior was small in most cases. That is, the time between when the male first grasped the female and started holding her in an opposed position and the time of copulation was less than two minutes in three of the four cases that ended in copulation. The female was either soft from a recent moult (four cases) or molted later that day. In one case the female had new eggs on her pleopods just two hours after copulation but the time of egg deposition was not known in the other cases.

The numbers of $C$. seurati available were far less than for C. zebra and they did not appear to be as active sexually, thus a limited number of observations were possible. All interactions involved males in Nerita shells, either $N$. picea or $N$. polita. Of the five interactions observed, four resulted in copulation. Moreover, in three cases, the male was much larger than the female (e.g. $11.1 \mathrm{~mm} \mathrm{cl}$ holding $5.3 \mathrm{~mm} \mathrm{cl}$ female) and thus the female shell was quite small. In other interactions, the male rolled over on the "back" of his gastropod shell. Yet in both situations the male held the female shell without dropping it and executed precopulatory patterns smoothly. This is in contrast to males of C. zebra in Nerita or Trochus shells.

In the one case that did not result in copulation, the male occupied a Natica gualteriana shell and the interaction was interrupted by the approach of a much larger individual of Calcinus laevimanus.

\section{Fecundity of Calcinus seurati}

The number of eggs on the pleopods were counted for 14 female C. seurati. All occupied Nerita picea shells. The mean number of eggs was 413 and ranged from 3 to 691 . The very low counts were all from females that had what appeared to be a black fungus on the egg-attachment ligaments and very few eggs still attached. Most of the variance in egg counts was explained by female size (number of eggs $=(218)(\mathrm{cl}$ in $\mathrm{mm})-1226, r=0.713$, 
$P=0.004)$. Consideration of additional factors (shell volume, volume deficit, shell weight) did not add significantly to the variance explained. Given the uniformity of shell species occupied, this factor could not be analyzed.

\section{Discussion}

The reproductive success of males in many species of animals increases with age and size (Arak 1988; Zuk 1988). In some cases this appears to be the result of female choice, either of the larger males per se (Arnold 1983; Hastings 1988; Hyatt 1977) or of resources such as territories which are more readily acquired by larger and/or more experienced males (Abele, Campanella and Salmon 1986; Christy and Salmon 1984; Tsubaki and Ono 1987). In other cases, the advantage of larger males is a result of intrasexual interactions and the resultant differential access to females (Halliday 1978; Johnson 1988). In the case of the hermit crab Clibanarius zebra, male size would appear to confer little in the way of a reproductive advantage except that larger males that do mate do so with larger (thus more fecund) females. However, larger males were at disadvantage since the shell species most available and occupied by larger males of C. zebra was Trochus intextus. Occupation of that species of gastropod shell had very serious consequences in terms of male reproductive success. Males in Trochus were both easily interrupted by other crabs and tended to be unable to handle the female in such a way that precopulatory patterns lead to mating. While experimentation is needed, it appears that the top-heavy nature of Trochus shells and its round (vs. ovoid) aperature make handling objects difficult for C. zebra.

On the basis of a limited number of observations, Bertness (1981) suggested for hermit crabs in general, that large males have a strong mating advantage and that sexual selection might explain the larger size of males. This would not seem to be the case in the two generalist species examined in more detail except that very small males do not obtain any matings. We can estimate the reproductive potential per attempt for males of different size classes as the product of the probability that a male in that size class will obtain a mating in open competition and the mean number of eggs carried by a female that he can copulate with (female size taken from the raw data and fecundity estimated from the regression between female size and egg counts). If we plot reproductive potential against male size (Fig. 3) we see that males of Clibanarius zebra below $6.0 \mathrm{~mm}$ cephalothorax length

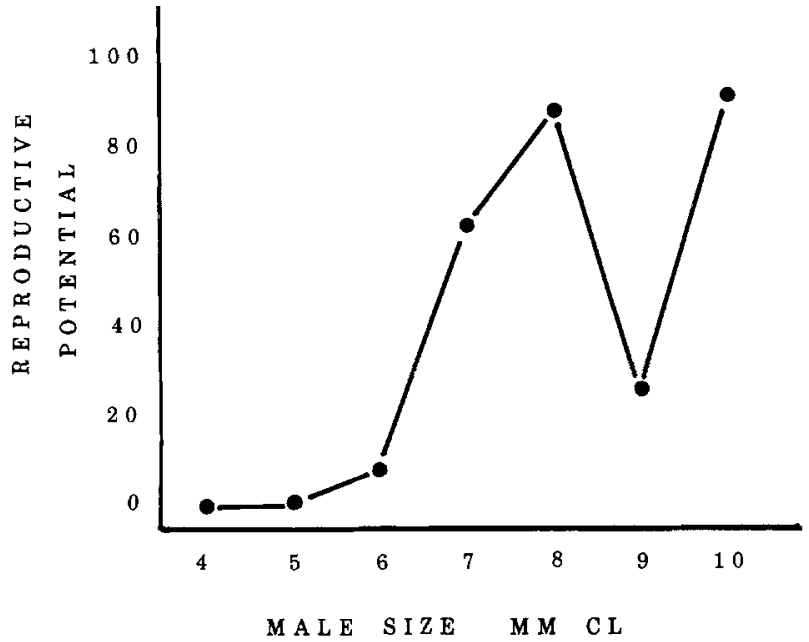

Fig. 3. Relationship between male size and reproductive potential. The latter is the product of the probability of a male mating times the number of eggs he would fertilize given the size of females with whom he can mate

have a much lower potential but that above $7.0 \mathrm{~mm} \mathrm{cl}$ there does not appear to be any clear trends.

The situation for C. zebra appears very similar to that of another shell generalist, the Caribbean diogenid Calcinus tibicen (Hazlett and Baron, in press). In this species the largest males occupied shells (Nerita and Cittarium) which made it almost impossible for the male crabs to execute precopulatory patterns properly. Thus as with C. zebra, the type of shells available to larger males in each species resulted in a reduction of their reproductive potential by making it difficult for males to execute the patterns which females apparently use to indicate that a crab is an appropriate mate. The pattern of rotation is the most common precopulatory act by males and while further work is needed, it may be that the ambulatory legs of the male are not able to move properly due to the shape of the aperature of some shell types. In both species of generalists, the rate of execution of precopulatory patterns was not markedly different by males in different species of shells. But the response of females to those patterns appeared different depending upon the species of shell occupied by males. That is, the number of rotations or the rate of rotations for a given number of minutes was the same in the case of $C$. zebra males in different species of shells but in the case of males in Trochus or Nerita this did not lead to copulation while those behavior patterns by males in other species of gastropod did lead to copulation.

It is unclear why female C. zebra did not appear to respond to the precopulatory patterns executed 
by males in "bad" shells while they did react to similar numbers of those patterns when executed by males in "good" shells. The male's shell provides no resources to the female nor to her offspring. Moreover, the occupation of a shell is a temporary condition for a hermit crab and it is hard to imagine that his behavior in one type of shell could be utilized to judge a male to be less desired as a potential gene source compared to another male. While the latter explanation (female selecting good genes as indicated by male behavior) can not be ruled out, an alternative possibility which involves fewer assumptions seems more likely. That is mistaken categorization by the human observer.

Assuming that female crabs use precopulatory patterns of males to make decisions concerning whether to mate or not, it is possible that what looks like rotations or inverse raps to the observer (and thus are scored as such) are not perceived that way by the female crab. When a male improperly executes behavior patterns the female may not respond because he has failed to signal that he is an appropriate partner. Thus the female would be choosing between the class of crabs 'appropriate' (executed patterns which identified the male as the right species, sex, motivation level, etc.) and the class of crabs 'inappropriate' (identifying patterns not executed).

The number of inverse raps executed by males of Clibanarius zebra was higher in interactions which resulted in copulation. However, it is not clear if that pattern effects female behavior or is effected by female behavior (or both). That is, inverse raps were more common just before copulation and often were preceeded by one or more bouts of palpations by the female. Thus inverse raps may be more an indicator of an impending copulation rather than an act which alters the female crab's reproductive motivation. It is curious that in the few cases where the male $C$. zebra walked away from the female without any "provocation' that the number of rotations executed was quite high ( 8.2 per interaction compared to 4.8 in those that resulted in copulation). Clearly the functions of these patterns are not well understood.

The reasons for the occupation of "bad" shells by larger males in the Hawaii compared to the Caribbean species are apparently different. In the case of Calcinus tibicen, larger individuals simply do not have a choice of large shells of the appropriate shape (Hazlett and Baron, in press). Such shells are in very limited supply in the environment. In Hawaii, larger males of Clibanarius zebra can not occupy Nassarius or Drupella shells of suf- ficient size simply because those gastropods do not grow large enough. However, large Turbo shells do occur in the environment but are occupied by individuals of Calcinus laevimanus, which overlap in distribution with C. zebra. Interspecific shells exchanges do occur but larger individuals of $C$. laevimanus will not readily give up Turbo shells for Trochus shells (Hazlett, unpublished data) and thus the supply of good-shaped, large shells is limited.

The experiments with putting males that occupied "good" shells in the field in "bad" shells and vice-versa demonstrated that the performance of males in the different categories of shells is a consequence of the shell species occupied. The alternative, that males in the "bad" shells were in such shells because they could not execute good behavior patterns in general seems unlikely given the results of the shell change experiments.

The behaviors observed in the shell specialist Calcinus seurati were in strong contrast to those of Clibanarius zebra or the caribbean species Calcinus tibicen. In particular, males of $C$. seurati were very capable of handling female shells and executing precopulatory patterns when occupying a shape of shell (Nerita) which the other crab species can not do well in and in which they can not successfully mate. It is a most interesting question whether this is a result of past selective pressures or a result of a life-time of experience with one shell type for most $C$. seurati. Individuals of $C$. seurati hold their ambulatory legs out to the side more than individuals of $C$. zebra and this may facilitate handling objects while in a shell type with a round aperature. The shell array available to individuals of $C$. seurati is much more predictable (always dominated by Nerita sp.) than the shell array which an individual of C. zebra or C. tibicen is likely to face (see Bertness 1980 for additional examples). Given those levels of environmental predictability, any mutations in $C$. seurati which resulted in improved performance in the limited environment that species occurs in would be favored, whereas mutations in C. zebra or C. tibicen which lead to either limited shell selection or improved performance in one shell type at the expense of performance in other shell types would be a disadvantage for crabs which may be faced with a wide array of shell species.

Experiments are needed to see if shell generalists and specialists differ in their abilities to learn to handle and behave in new shell types. As crabs grow, they encounter new shell species but this occurs much more frequently for some crabs species than for others. The consequences of poor shell 
handling would seem to be especially strong for male hermit crabs.

Acknowledgments. This is contribution number 781 from the Hawaii Institute of Marine Biology. This work was supported by NSF grant BNS-8604092 from the Psychobiology Program. Thanks are given to Ernic Reese and Frank Stanton for their help and hospitality.

\section{References}

Abele LG, Campanella FG, Salmon M (1986) Natural history and social organization of the semiterrestrial grapsid crab Pachygrapsus transversus (Gibbes). J Exp Mar Biol Ecol 104:153-170

Arak A (1988) Female male selection in the natterjack toad: active choice or passive attraction. Behav Ecol Sociobiol $22: 317-327$

Arnold SJ (1983) Sexual selection: the interface of theory and empiricism. In Mate Choice, P. Bateson (ed) Cambridge Univ. Press, Cambridge, pp 67-107

Bertness MD (1980) Shell preference and utilization patterns in littoral hermit crabs of the Bay of Panama. J Exp Mar Biol Ecol 48:1-16

Bertness MD (1981) Interference, exploitation, and sexual components of competition in a tropical hermit crab assemblage. J Exp Mar Biol Ecol 49:189-202

Borgia G (1979) Sexual selection and the evolution of mating systems. In Sexual selection and reproductive competition in insects, Blum MS \& Blum NA (eds), Academic Press, NY pp 19-80

Christy JH, Salmon M (1984) Ecology and evolution of mating systems of fiddler crabs (Genus $U c a$ ). Biol Rev 59:483-509

Halliday TR (1978) Sexual selection and mate choice. In Behavioural Ecology an evolutionary approach, Krebs JR, Davies NB (eds), Sinauer, Sutherland, Mass, pp 180-213
Hastings PA (1988) Correlates of male reproductive success in the browncheek blenny, Acanthemblemaria crocker (Blennioidea: Chaenopsideae). Behay Ecol Sociobiol 22:95102

Hazlett BA (1966) Social behavior of the Paguridae and Diogenidae of Curacao. Stud Fauna Curacao 23:1-143

Hazlett BA (1968) The sexual behavior of some European hermit crabs. Pubbl Staz Zool Napoli 36:238-252

Hazlett BA (1972) Shell fighting and sexual behavior in the hermit crab genera Paguristes and Calcinus, with comments on Pagurus. Bull Mar Sci 22:806-823

Hazlett BA, Baron LC. Influence of shells on mating behavior in the hermit crab Calcinus tibicen. Behav Ecol Sociobiol $24: 369-376$ (in press)

Hyatt GW (1977) Field studies of size-dependent changes in waving display and other behvior in the fiddler crab, $U c a$ pugilator (Brachyura, Ocypodidae). Mar Behav Physiol $4: 283-292$

Johnson K (1988) Sexual selection in pinyon jays I: female choice and male-male competition. Anim Behav 36:1038-1047

Reese ES (1968) Annual breeding seasons of three sympatric species of tropical intertidal hermit crabs, with a discussion of factors controlling breeding. J Exp Mar Biol Ecol $2: 308-318$

Reese ES (1969) Behavioral adaptations of intertidal hermit crabs. Am Zool 9:343-355

Tsubaki Y, Ono T (1987) Effects of age and body size on the male territorial system of the dragonfly, Nannophya pygmaea Rambur (Odonata: Libellulidae). Anim Behav $35: 518-525$

Wooster DS (1984) The genus Calcinus (Paguridae, Diogenidae) from the Mariana Islands including three new species. Micronesica 18:121-162

Zuk M (1988) Parasite load, body size, and age of wild-caught male field crickets (Orthoptera: Gryllidae): effects on sexual selection. Evolution 42:969-976 